\title{
Incidence of heart failure in infarcted rats that die spontaneously
}

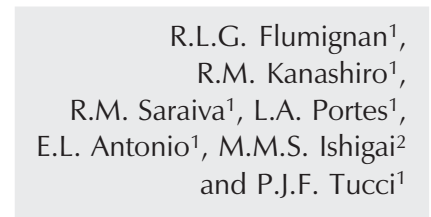

${ }^{1}$ Divisão de Fisiologia Cardiovascular, ${ }^{2}$ Divisão de Patologia, Universidade Federal de São Paulo, São Paulo, SP, Brasil

\section{Correspondence \\ P.J.F. Tucci \\ Divisão de Fisiologia Cardiovascular UNIFESP \\ R. Estado de Israel, 181/94 04022-000 São Paulo, SP Brasil \\ Fax: +55-11-5083-3735 \\ E-mail: tucci@fcr.epm.br}

Research supported by $\mathrm{CNPq}$ (No. 300.692/80-3NV) and FAPESP (No. 99/04533-4).

Received September 23, 2005 Accepted June 30, 2006 $\ldots \ldots \ldots \ldots \ldots \ldots \ldots$

\section{Abstract}

The present study reports for the first time the incidence of congestive heart failure $(\mathrm{CHF})$ in previously infarcted rats that died spontaneously. Previously, pulmonary (PWC) and hepatic (HWC) water contents were determined in normal rats: 14 control animals were evaluated immediately after sacrifice, 8 placed in a refrigerator for $24 \mathrm{~h}$, and 10 left at room temperature for $24 \mathrm{~h}$. In the infarcted group, 9 rats died before (acute) and 28 died $48 \mathrm{~h}$ after (chronic) myocardial infarction. Thirteen chronic animals were submitted only to autopsy $(\mathrm{N}=13)$, whereas PWC and HWC were also determined in the others $(\mathrm{N}=15)$. Seven rats survived $48 \mathrm{~h}$ and died during anesthesia. Notably, PWC differed in normal rats: ambient $(75.7 \pm 1.3 \%)<$ control $(77.5 \pm 0.7 \%)$ $<$ refrigerator $(79.1 \pm 1.4 \%)$ and there were no differences with respect to HWC. No clinical signs of CHF (dyspnea, lethargy or foot edema) were observed in infarcted rats before death. PWC was elevated in all chronic and anesthetized rats. HWC was increased in $48 \%$ of chronic and in all anesthetized rats. Our data showed that PWC needs to be evaluated before $24 \mathrm{~h}$ post mortem and that $\mathrm{CHF}$ is the rule in chronic infarcted rats suffering natural death. The congestive syndrome cannot be diagnosed correctly in rats by clinical signs alone, as previously proposed.

\section{Introduction}

Experimental models have proven to be valuable to clarify important topics related to the pathophysiology, treatment, prognosis, and survival of animals with congestive heart failure (CHF). However, some fundamental information on experimental models of $\mathrm{CHF}$ is lacking. As a matter of fact, even though the incidence and prevalence of heart failure following a myocardial infarction (MI) have been extensively studied in humans (1-5), no data on heart failure incidence are available
Key words

- Heart failure

- Myocardial infarction

- Rats

- Pulmonary congestion

- Hepatic congestion ......................... about the widely recognized experimental murine model of MI.

The present study reports the incidence of CHF in previously infarcted rats that died spontaneously. Autopsy was performed on all infarcted female rats that died spontaneously throughout one year in our laboratory, with special emphasis on the signs of pulmonary and/or hepatic congestion. Even though $\mathrm{CHF}$ is not always present in human deaths with reports of previous infarction, we showed that $\mathrm{CHF}$ is a rule in rats that die spontaneously more than $48 \mathrm{~h}$ after MI. 


\section{Material and Methods}

The rats were cared for in compliance with the Principles of Laboratory Animal Care formulated by the National Institute of Health (National Institute of Health publication No. 96-23, revised, 1996) according to the protocol approved by the Ethics Research Committee of the Federal University of São Paulo, Brazil.

Female Wistar rats (180 to $220 \mathrm{~g}$ ) were subjected to MI according to a well-accepted technique (6-8). Briefly, left thoracotomy was performed after anesthesia with a mixture of ketamine $(50 \mathrm{mg} / \mathrm{kg})$ and xylazine $(10 \mathrm{mg} / \mathrm{kg})$. The heart was exteriorized and the anterior descending coronary artery ligated with 6-0 polypropylene. The heart was quickly returned to its position and the thorax immediately closed.

The rats were housed in clear polyethylene cages under controlled temperature (22 $\pm 1^{\circ} \mathrm{C}$ ), humidity and light/dark cycles (12/ $12 \mathrm{~h}$ ), with free access to food and water. The infarcted sample consisted of consecutive cases of female rats that had died naturally over a period of one year and that could be evaluated in due time.

Seventy-six rats were divided into seven groups according to the time and conditions of evaluation. Initially, three groups of normal rats were studied to determine pulmonary (PWC) and hepatic (HWC) water contents in order to define whether normal tissue water content is altered when autopsy is performed $24 \mathrm{~h}$ after death. PWC and HWC were determined in 14 control rats (control group) immediately after sacrifice with an overdose of thiopental. Eight other rats were sacrificed and maintained for $24 \mathrm{~h}$ in a refrigerator at a controlled temperature of 2$5^{\circ} \mathrm{C}$ (group $24 \mathrm{~h}$ in refrigerator: $24 \mathrm{R}$ ), and ten rats were sacrificed and maintained for $24 \mathrm{~h}$ at room temperature $\left(21-24^{\circ} \mathrm{C}\right)$ before tissue water content was determined (group $24 \mathrm{~h}$ at ambient temperature: 24A).

Forty-four infarcted animals were ana- lyzed in four other groups according to ensuing conditions. Nine animals recovered from anesthesia, awoke, and died within $48 \mathrm{~h}$ of coronary occlusion (acute group: Ac). Two chronic groups (survival of at least $48 \mathrm{~h}$ after coronary occlusion) included rats that were submitted to autopsy with histopathologic evaluation (Ch-N: $\mathrm{N}=13$ ) or analyzed for PWC and HWC (Ch-W: N = 15). Seven other animals that survived $48 \mathrm{~h}$ after acute MI and died during anesthesia for echocardiographic examination also had PWC and HWC determined (anesthesia group: An). In the animals used for water content evaluation necropsy was necessarily limited to macroscopic analysis.

\section{Autopsies}

All animals were submitted to complete macroscopic evaluation, except for the central nervous system, within $24 \mathrm{~h}$ after death, with the aim of evaluating the occurrence of CHF. All thoracic and abdominal organs were analyzed with particular emphasis on heart size, intracavitary thrombus, pulmonary congestion or hemorrhage, hydrothorax, ascites, edema, and liver congestion. In addition, heart, lung and liver slices were evaluated in the Ch-N group. One-millimeter sections were cut transversely along the left ventricular major axis at the midpoint from the apex to the base of the heart and dehydrated in alcohol, cleared in xylene and embedded in paraffin. The blocks were sliced and stained with hematoxylin-eosin and Masson's trichrome to characterize MI size. Lung and liver samples were fixed in $10 \%$ phosphate-buffered formalin for $24 \mathrm{~h}$ and prepared for routine histopathologic examination with hematoxylin-eosin staining. Hepatic and/or lung edema, enlargement of the alveolar wall, fluid edema in alveolar spaces, and chronic passive liver congestion were accepted as signs of CHF. The histological slices of 13 rats were used to measure MI size. These sections were stained, photo- 
graphed and analyzed with the Image Tool $3.00^{\circledR}$ software (The University of Texas Health Science Center, San Antonio, TX, USA) in order to determine 1) left ventricle (LV) circumference, and 2) length of the infarcted portion of LV myocardium at the midpoint of the chamber wall. MI sizes were determined by estimating the percentage of LV circumference occupied by a MI fibrous scar $(6,9)$.

\section{Pulmonary and hepatic water content}

In the excised lung and liver tissues from 31 infarcted rats (Ac, Ch-W, and An) evaluated within $12 \mathrm{~h}$ after death, wet weight (WW) and dry weight (DW) were determined before and after drying the samples at $70^{\circ} \mathrm{C}$ in a negative vacuum pressure of -760 $\mathrm{mmHg}$ until they achieved a constant weight. Water content $\left(\% \mathrm{H}_{2} \mathrm{O}\right)$ was estimated using the formula:

$$
\% \mathrm{H}_{2} \mathrm{O}=[(\mathrm{WW}-\mathrm{DW}) / \mathrm{WW}] \times 100
$$

\section{Statistical analysis}

Data are reported as means \pm SD. Differences between groups were compared (Sigma Stat ${ }^{\circledR}$ 2.0, SPSS Inc., Chicago, IL, USA) by one-way ANOVA followed by the StudentNewman-Keuls test, with the level of significance set at $\mathrm{P}<0.05$.

\section{Results}

\section{Necroscopic studies}

MI occupied $42 \pm 16 \%$ (range: 24 to $68 \%$ ) of the ventricular perimeter of the rats studied at autopsy.

Evidence of pulmonary congestion was found in $12(92.3 \%)$ of $13 \mathrm{Ch}-\mathrm{N}$ rats, while hepatic congestion was found in $5(38 \%)$. The only Ch-N animal that did not present evidence of CHF had probable lung congestion and subtle chronic passive liver conges- tion. These circumstances did not allow us to affirm the presence of overt CHF; however, congestive syndrome could not be ruled out and was quite probably present.

Three animals showed signs of cardiopulmonary infection disease. One died 61 days after coronary occlusion, and revealed a large purulent pleural collection. The other two rats died 5 and 7 days after surgery and had discrete fungus pericarditis characterized by hematoxylin-eosin plus Gram and PAS staining. Hydrothorax was present in three rats, ascites in one and hemothorax associated with a pulmonary infarction in one. Pedal edema was not found in any of these rats.

\section{Water content}

Differences were noted between the three groups analyzed to determine the influence of the time elapsed after death on tissue water content (Figure 1). Curiously, animals left at ambient temperature for $24 \mathrm{~h}$ presented a lower PWC (24A group: $75.7 \pm$ $1.3 \% ; \mathrm{P}<0.05)$ than rats examined immediately (control group: $77.5 \pm 0.7 \%$ ), while animals maintained in a refrigerator revealed higher values $(\mathrm{P}<0.05)$ of $\mathrm{PWC}(24 \mathrm{R}$ group: $79.1 \pm 1.4 \%)$. No significant differences were noted with respect to HWC (control:

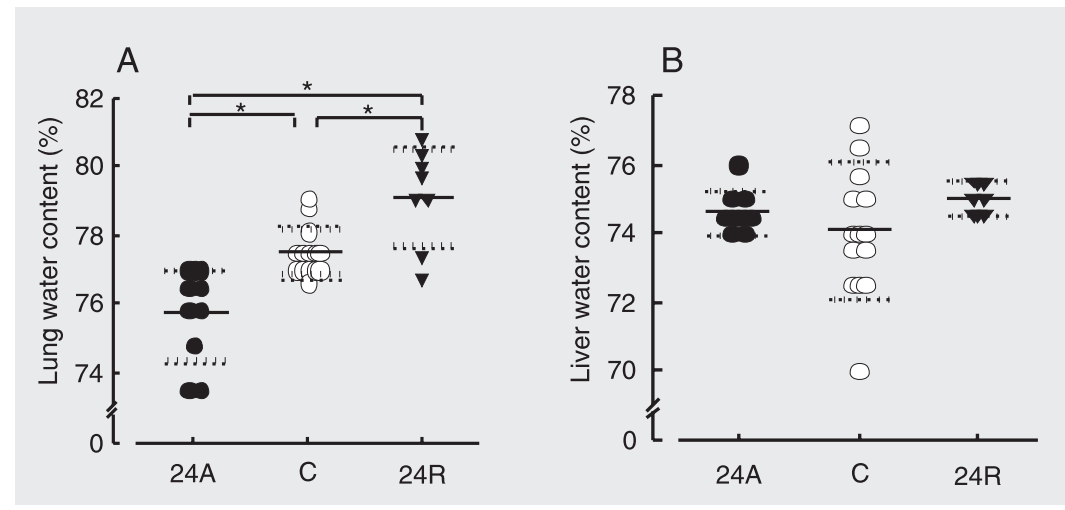

Figure 1. Lung (A) and liver (B) water content in control rats submitted to autopsy after being maintained for $24 \mathrm{~h}$ post mortem at room temperature (24A: $N=10$ ), immediately after death $(\mathrm{C}: \mathrm{N}=14)$, and after the rats being maintained for $24 \mathrm{~h}$ in a refrigerator $(24 \mathrm{R}: \mathrm{N}=8)$. Data are reported as the mean (horizontal solid lines) $\pm \mathrm{SD}$ (dotted lines). ${ }^{*} \mathrm{P}<0.05$ (oneway ANOVA plus the Student-Newman-Keuls test). 
$74.1 \pm 1.9 \%$; $24 \mathrm{~A}: 74.6 \pm 0.6 \%$; 24R: $75 \pm$ $0.5 \%)$.

PWC was used as an indicator of leftsided heart failure (LSHF) and HWC as an indicator of right-sided heart failure (RSHF). The results (Figure 2) revealed LSHF and RSHF in both chronic groups of infarcted rats. In fact, PWC (Figure 2A) and HWC (Figure 2B) of An $(80.6 \pm 0.7$ and $76.1 \pm$ $0.6 \%$, respectively) and $\mathrm{Ch}-\mathrm{W}$ animals (81.6 \pm 2.0 and $75.6 \pm 2.0 \%$, respectively) were significantly higher than those of control $(77.5 \pm 0.7$ and $74.1 \pm 1.9 \%$, respectively $)$ and Ac $(77.7 \pm 1.9$ and $72.9 \pm 0.8 \%$, respectively) animals. There were no differences between control and Ac with respect to PWC or to HWC.

CHF was considered to be present when the water content of an animal was equal to or higher than the mean plus two standard deviations $(x+2 S D)$ of control in the lung and/or in the liver.

In the Ch-W group, only one rat presented PWC equal to $\mathrm{x} \pm 2 \mathrm{SD}$ of control; all the other $\mathrm{Ch}-\mathrm{W}$ rats presented PWC higher than $x \pm 2$ SD of control. Similarly, all the rats of the An group presented PWC higher than $\mathrm{x} \pm 2 \mathrm{SD}$ of control. Only one animal of the Ac group had an abnormal PWC, thus leading us to conclude that this animal probably died in LSHF.
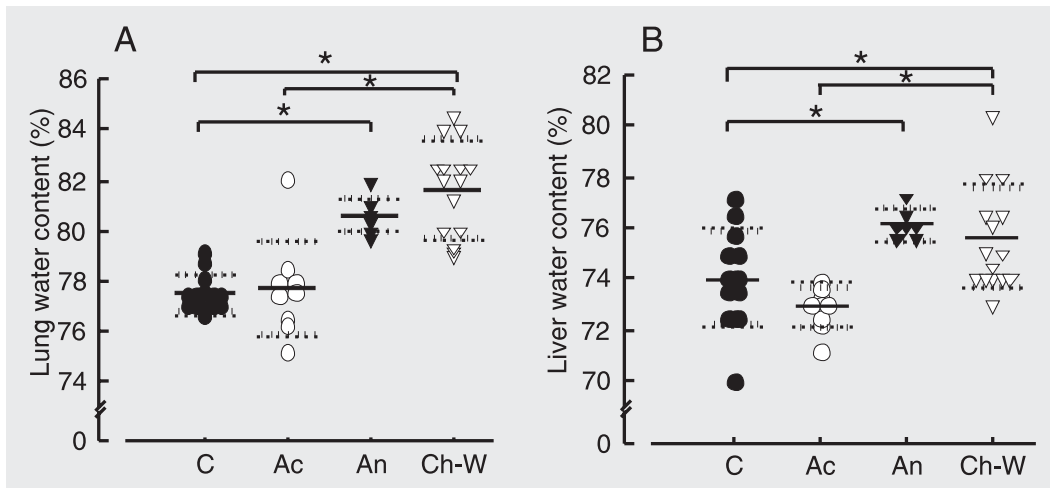

Figure 2. Lung (A) and liver (B) water content in control rats $(C: N=14)$ and in infarcted rats that died in the acute period (Ac: $N=9$ ), during anesthesia (An: $N=7$ ) or in the chronic period (Ch-W: $N=15)$. Data are reported as the mean (horizontal solid lines) $\pm S D$ (dotted lines). ${ }^{*} P<0.05$ (one-way ANOVA plus the Student-Newman-Keuls test).
Using the control values as the index for determining individual RSHF, it was not possible to identify particular cases of hepatic congestion in the An and $\mathrm{Ch}-\mathrm{W}$ groups, even though mean HWC values for the An and $\mathrm{Ch}-\mathrm{W}$ groups were significantly higher compared to control rats. This seems to be dependent on the inexplicably high values of the standard deviation in control. Nevertheless, assuming that the Ac rats were devoid of RSHF, and taking their values for comparison purposes, we were able to conclude that all An rats and $53 \%$ ( 8 of 15) of the rats in the $\mathrm{Ch}-\mathrm{W}$ group presented RSHF.

\section{Discussion}

An interesting methodological aspect emerges from the analyses of different noninfarcted groups. In these groups, it was shown that for rats analyzed $24 \mathrm{~h}$ after death, the PWC depends on the distinct conditions used to maintain the animals post mortem. Indeed, when the rats were left at room temperature (24A group) the values of PWC decreased when compared with those of rats immediately submitted for evaluation (control group), in contrast to the increased PWC values detected in the rats maintained in a refrigerator (24R group). Considering the elevated normal PWC $(77.5 \pm 0.7 \%)$, we may assume that the lower level of room air humidity allowed water evaporation from lung tissue, thus resulting in a reduced amount of PWC. In contrast, it seems that the humid environment of the refrigerator induced water uptake by the tissue of the rats of the 24R group. This interpretation is consistent with the fact that the water content of an organ that has no direct contact with the environment - the liver - was not influenced by the external milieu. These results support the view that when determining tissue composition we need to take into account that the volatile components of an organ in contact with the surrounding environment are affected by these external environmental fac- 
tors. Overall, these results suggest that PWC should be analyzed within less than $24 \mathrm{~h}$ after death.

To the best of our knowledge, there are no previous data on $\mathrm{CHF}$ incidence in rats subjected to coronary occlusion that die spontaneously. Previous papers referred to pulmonary congestion in infarcted rats evaluated after the rodents were sacrificed, one week after coronary occlusion or later (10$16)$, with pulmonary congestion characterized by average group values - so much so, that the individual presence of heart failure could not be recognized.

When CHF was analyzed taking PWC into account, our results showed that LSHF occurred in all infarcted rats that died $48 \mathrm{~h}$ after coronary occlusion or later. Likewise, the autopsies showed that all but one rat revealed definitive evidence of pulmonary congestion in pathological analysis. The only animal in the $\mathrm{Ch}-\mathrm{N}$ group not included in those affected by evident heart failure presented poorly defined manifestations of pulmonary edema. CHF cannot be ruled out in this animal. Accordingly, it seems reasonable that $\mathrm{CHF}$ is common in infarcted rats that die spontaneously, with a wide range of MI size (24 to $68 \%$ of LV) in the chronic period after coronary occlusion. In addition to clear indications of LSHF, liver congestion was observed in approximately half of our chronically infarcted animals, suggesting RSHF associated with LSHF. Therefore, our data indicate the possibility of some form of CHF in all rats that die spontaneously after $48 \mathrm{~h}$ of coronary occlusion.

On the other hand, heart failure was not a frequent finding in rats that died within $48 \mathrm{~h}$ of coronary occlusion. Indeed, hepatic congestion did not occur and pulmonary congestion was found in only 1 of $9(11 \%)$ of these rodents. Previous papers $(17,18)$ have shown that in the rat the deaths occurring during the acute period of coronary occlusion are due to cardiac arrhythmias. Thus, the uncommon CHF in our acute group is in keeping with the idea that the congestive syndrome is not a frequent disturbance in rats that die in the acute phase of coronary occlusion, as occurs in chronic cases.

The indiscriminate increase in PWC and HWC in rats that died during anesthesia deserves some attention. These results indicate that, although these animals did not present a critical clinical state, they were in high anesthetic risk, probably due to CHF, and this fact supports the idea that infarcted rats that die after $48 \mathrm{~h}$ of coronary occlusion suffer from a congestive state. Moreover, as these rats did not exhibit any clinical signs indicating $\mathrm{CHF}$, a notable point emerges from our data: it now appears incorrect to consider that a diagnosis of heart failure can be performed precisely in infarcted rats, when attempted in the presence of dyspnea, lethargy or pedal edema, as previously proposed (19-22).

Taking into account the recognized gender peculiarities of myocardium remodeling and heart failure $(23,24)$, our data are inevitably limited in the sense that the omnipresence of $\mathrm{CHF}$ in chronically infarcted rats that die spontaneously might be restricted to females until the same result can be verified in males.

Finally, it should be pointed out that our data do not permit speculation as to the cause of death of these rodents. In humans, it is firmly believed (25) that for half of the patients with chronic $\mathrm{CHF}$, death occurs by progressive intensification of the congestive state, while in the remaining half arrhythmias are the cause of death. In experimental models of chronic heart failure there is no information concerning the cause of death.

\section{Acknowledgments}

Special thanks are due to Regina H.E. Alfarano, PhD, New York University, for revision of language and style. 


\section{References}

1. Emanuelsson H, Karlson BW, Herlitz J. Characteristics and prognosis of patients with acute myocardial infarction in relation to occurrence of congestive heart failure. Eur Heart $J$ 1994; 15: 761-768.

2. Moss AJ, Benhorin J. Prognosis and management after a first myocardial infarction. N Engl J Med 1990; 322: 743-753.

3. Hellermann JP, Jacobsen SJ, Redfield MM, Reeder GS, Weston SA, Roger VL. Heart failure after myocardial infarction: clinical presentation and survival. Eur J Heart Fail 2005; 7: 119-125.

4. Hellermann JP, Jacobsen SJ, Gersh BJ, Rodeheffer RJ, Reeder GS, Roger VL. Heart failure after myocardial infarction: a review. Am J Med 2002; 113: 324-330.

5. de Kam PJ, Nicolosi GL, Voors AA, van den Berg MP, Brouwer J, van Veldhuisen DJ, et al. Prediction of 6 months left ventricular dilatation after myocardial infarction in relation to cardiac morbidity and mortality. Application of a new dilatation model to GISSI-3 data. Eur Heart J 2002; 23: 536-542.

6. Fishbein MC, Maclean D, Maroko PR. Experimental myocardial infarction in the rat: qualitative and quantitative changes during pathologic evolution. Am J Pathol 1978; 90: 57-70.

7. Johns TNP, Olson BJ. Experimental myocardial infarction. I. A method of coronary occlusion in small animals. Ann Surg 1954; 140: 675-682.

8. Pfeffer MA, Lamas GA, Vaughan DE, Parisi AF, Braunwald E. Effect of captopril on progressive ventricular dilatation after anterior myocardial infarction. N Engl J Med 1988; 319: 80-86.

9. Moises VA, Ferreira RL, Nozawa E, Kanashiro RM, Campos O, Andrade JL, et al. Structural and functional characteristics of rat hearts with and without myocardial infarct. Initial experience with Doppler echocardiography. Arq Bras Cardiol 2000; 75: 125-136.

10. Francis J, Weiss RM, Wei SG, Johnson AK, Felder RB. Progression of heart failure after myocardial infarction in the rat. Am J Physiol 2001; 281: R1734-R1745.

11. Clozel M, Qiu C, Qiu CS, Hess P, Clozel JP. Short-term endothelin receptor blockade with tezosentan has both immediate and longterm beneficial effects in rats with myocardial infarction. J Am Coll Cardiol 2002; 39: 142-147.

12. Nakamura R, Kato J, Kitamura K, Onitsuka H, Imamura T, Cao Y, et al. Adrenomedullin administration immediately after myocardial infarction ameliorates progression of heart failure in rats. Circulation 2004; 110: 426-431.

13. Saito T, Hu F, Tayara L, Fahas L, Shennib H, Giaid A. Inhibition of NOS II prevents cardiac dysfunction in myocardial infarction and congestive heart failure. Am J Physiol 2002; 283: H339-H345.

14. Saito T, Rodger IW, Hu F, Shennib H, Giaid A. Inhibition of cyclooxy- genase-2 improves cardiac function in myocardial infarction. Biochem Biophys Res Commun 2000; 273: 772-775.

15. Theilade J, Strom C, Christiansen T, Haunso S, Sheikh SP. Differential $\mathrm{G}$ protein receptor kinase 2 expression in compensated hypertrophy and heart failure after myocardial infarction in the rat. Basic Res Cardiol 2003; 98: 97-103.

16. Zheng B, Cao LS, Zeng QT, Wang X, Li DZ, Liao YH. Inhibition of NOS2 ameliorates cardiac remodeling, improves heart function after myocardial infarction in rats. Basic Res Cardiol 2004; 99: 264-271.

17. Leenen FH, Yuan B. Mortality after coronary artery occlusion in different models of cardiac hypertrophy in rats. Hypertension 2001; 37: 209-215.

18. Opitz CF, Mitchell GF, Pfeffer MA, Pfeffer JM. Arrhythmias and death after coronary artery occlusion in the rat. Continuous telemetric ECG monitoring in conscious, untethered rats. Circulation 1995; 92: 253-261.

19. Bing $\mathrm{OH}$, Brooks WW, Robinson KG, Slawsky MT, Hayes JA, Litwin $\mathrm{SE}$, et al. The spontaneously hypertensive rat as a model of the transition from compensated left ventricular hypertrophy to failure. $J$ Mol Cell Cardiol 1995; 27: 383-396.

20. Cicogna AC, Robinson KG, Conrad CH, Singh K, Squire R, Okoshi MP, et al. Direct effects of colchicine on myocardial function: studies in hypertrophied and failing spontaneously hypertensive rats. $\mathrm{Hy}$ pertension 1999; 33: 60-65.

21. Ikeda S, Hamada M, Hiwada K. Contribution of non-cardiomyocyte apoptosis to cardiac remodelling that occurs in the transition from compensated hypertrophy to heart failure in spontaneously hypertensive rats. Clin Sci 1999; 97: 239-246.

22. Khaper N, Singal PK. Modulation of oxidative stress by a selective inhibition of angiotensin II type 1 receptors in MI rats. J Am Coll Cardiol 2001; 37: 1461-1466.

23. Adams KF Jr, Sueta CA, Gheorghiade M, O'Connor CM, Schwartz TA, Koch GG, et al. Gender differences in survival in advanced heart failure. Insights from the FIRST study. Circulation 1999; 99 1816-1821.

24. Simon T, Mary-Krause M, Funck-Brentano C, Jaillon P. Sex differences in the prognosis of congestive heart failure: results from the Cardiac Insufficiency Bisoprolol Study (CIBIS II). Circulation 2001; 103: 375-380.

25. Givertz MM, Colucci WS, Braunwald E. Clinical aspects of heart failure; pulmonary edema, high-output failure. In: Zipes DP, Libby P, Bonow RO, Braunwald E (Editors), Braunwald's heart disease: $A$ text of cardiovascular medicine. 7th edn. Philadelphia: Elsevier Saunders; 2005. p 539-568. 